\title{
Urea Plant Energy Improved with Operation Philosophy \& Reactor Internals
}

\author{
Prem Baboo \\ Sr. Manager (Prod) \\ National fertilizers Ltd. India \\ Sr. Advisor of www.ureaknowhow.com
}

\begin{abstract}
The energy of H.P. loop directly proportional to the pressure of h.p loop. The H.P loop is the heart of urea plants. Conversion of urea depends upon N/C \& $\mathrm{H} / \mathrm{C}$ ratio, reactor internal construction, i.e. configuration of trays, reactants mixing phenomenon, flow pattern etc. other than pressure. In conventional plants there was too much pressure of the reactors for higher urea conversion. Now philosophy has been changed our mind concentrated on flow pattern of the fluid dynamics and internals of the reactors. The performances of Urea Reactors can be improved by the application of the latest generation of internals like HET, Vortex mixture and conversion booster. As a consequence, the HET \& Vortex mixture can be applied to design a new generation of urea reactors as well as to improve the performance of existing equipment in a retrofit design. The increase in the efficiency has permitted direct benefits to the overall day-by-day performances of the units, thus allowing lower energy consumption and a reduced environmental impact. The present paper based on these facts and how to improve energy by changing internals, operational parameters like molar ratio, recycling of water in the system, pressure \& temperature of the system to improve energy and equipment's life. The most important of these consists of a sharp reduction in specific steam consumption. The fluiddynamics of a urea reactor can be significantly improved by the introduction of the latest generation of internals. e.g. Super cup trays, Vortex mixture, NIIK internals, siphon jet trays etc. No pressure drop observed because the gas phase directly converted to liquid phase the driving force compensates the pressure drop and No load limitation.
\end{abstract}

Key words - Conversion, energy, Reactor, internals, trays, Vortex mixture. water recycling, HET, Super cup trays. Booster conversion, NIIK, Siphon-jet.

\section{INTRODUCTION}

National Fertilizers Ltd, (NFL) operates a fertilizer complex at Vijaipur, Distt. Guna (Madhya Pradesh), India consisting of two units Vijaipur-I and Vijaipur-II, plants were commissioned in December 1987 and March 1997 respectively. Ammonia Plants are based on M/s. HTAS's Steam Reforming of Natural Gas and Urea plants are based on M/S. Saipem's Ammonia Stripping Technology. NFL, a Schedule 'A' \& a Mini Ratna (Category-I) Company. The Vijaipur unit, which is an ISO 9001:2000 \& 14001 certified, comprises of two streams. The Vijaipur have two ammonia plant M/S. Haldor Topsoe Technology, Denmark capacity $1750 \& 1864$ TPD for Line-I \& line-II respectively and four urea plant of M/S. Saipem ammonia stripping process, Italy. The capacity of Urea-I urea -II is 3030 \& 3231 TPD respectively. In urea rectors line-1 \& 2 initially have 10 numbers of simple sieve trays (having 360 holes in each tray).In 2005 all four reactors replaced the simple sieve trays with M/S. Saipem design HET. The energy saving reported $0.02 \mathrm{G} . \mathrm{cal} /$ ton of urea. Now we are planning to install Vortex mixture with conversion Booster in bottom parts of reactor, the energy will be saved about $0.05 \mathrm{G}$.cal/ton of urea. This is the new technology for reactor for energy efficiency enhancement and developed by M/S.NIIK Russia and patented.

Energy Saving by operation Philosophy

The rate of urea reaction is directly proportional to

1. $\mathrm{N} / \mathrm{C}$ ratio

2. Temperature

3. System pressure

4. No. of particles collision with ammonia \& Carbon Dioxide (may be carried out with Vortex)

5. Surface area.

6. Active mass of the reaction(i.e. law of mass action)

7. To reduce $\mathrm{H} / \mathrm{C}$ ratio.

The speed of urea reaction varies hugely according to above. The minimum amount of energy needed for the $\mathrm{CO}_{2}$ \& ammonia to react is called the activation energy, and is different for each reaction. This activation energy can be supplied by internal flow dynamics of particles with some mechanical device like Vortex mixture \& conversion booster. The rate of a reaction depends on two things:

The frequency of collisions between particles and the energy with which particles collide. If particles collide (cyclonic) with less energy than the activation energy, they will not react. The higher the temperature, the faster the rate of a reaction. In many reactions, a rise in temperature of $10{ }^{\circ} \mathrm{C}$ causes the rate of reaction to approximately double. At a higher temperature, particles have more energy. This means they move faster and are more likely to collide with other particles. When the particles collide, they do so with more energy, and so the number of successful collisions increases. This collision phenomenon may be done with vortex mixture. The particles will just bounce off each other. Anything that increases the number of successful collisions between reactant particles will speed up a reaction. The turbulence is necessary to speed up of reaction. Reactions do not proceed at a steady rate. They start off at a certain speed, then get slower and slower until they stop. As the reaction progresses, the concentration of reactants decreases. This reduces the frequency of collisions between particles and so the reaction slows down. 


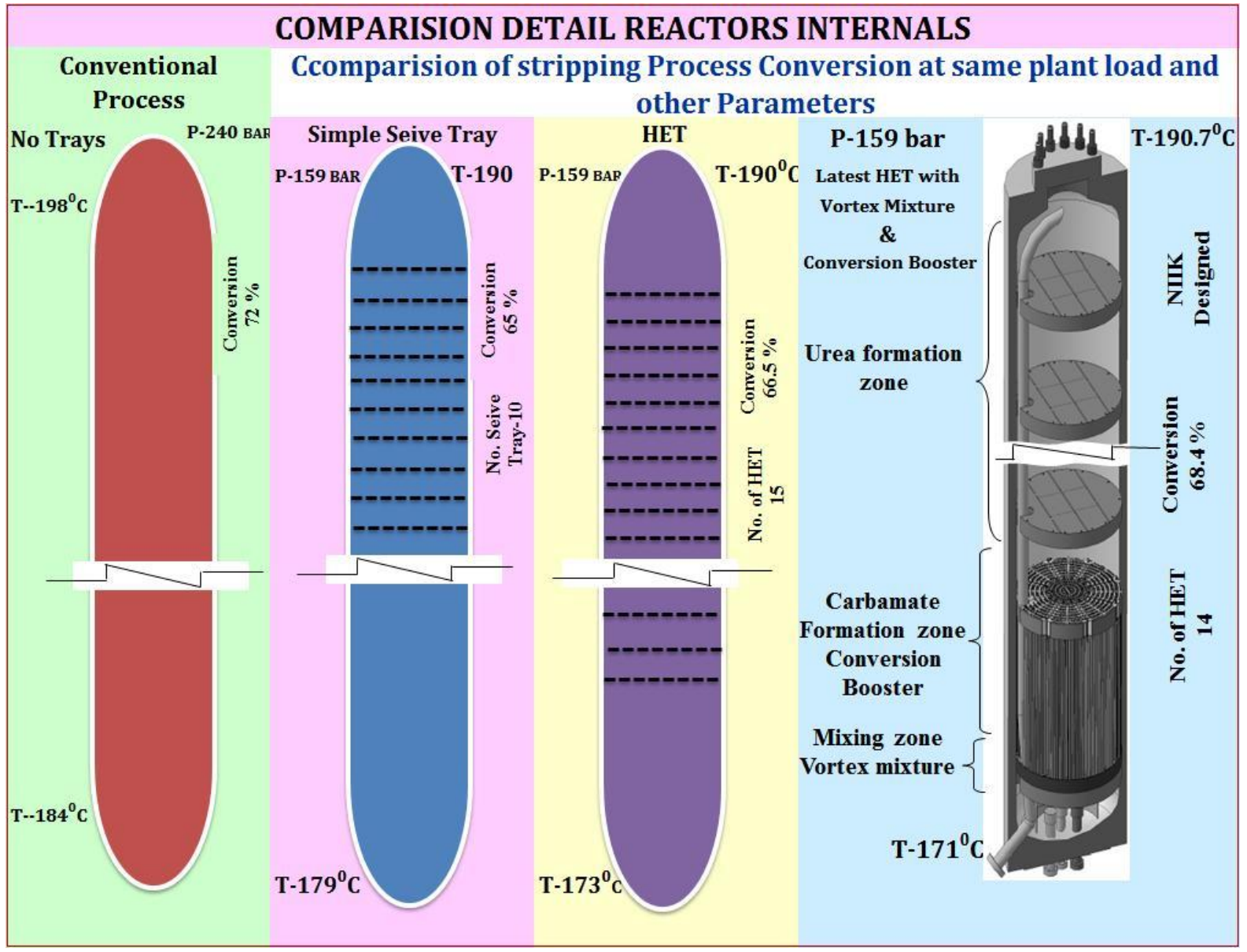

Fig -1(Comparison of Reactor internals/trays)

Following operation philosophy to improve the energy of urea plants.
1. $\mathrm{N} / \mathrm{C}$ ratio
2. $\mathrm{H} / \mathrm{C}$ ratio
3. Residence Time.
4. Reactors internals replaced with advance technology.

\section{N/C Ratio}

Theoretical mole ratio of $\mathrm{NH}_{3}: \mathrm{CO}_{2}$ is $2: 1$; but in this condition urea yield is only around $43.44 \%$ at $170 \mathrm{~kg} / \mathrm{cm} 2 \mathrm{a}$ and $155^{\circ} \mathrm{C}$. This low yield can be improved by changing $\mathrm{NH}_{3}: \mathrm{CO}_{2}$ ratio. When the excess ammonia is increased to 279 $\%$ (mole ratio of $\mathrm{NH}_{3} / \mathrm{CO}_{2}$ is increased), urea yield will change from 43.5 to $85.2 \%$. The excess of ammonia over that required to form ammonium carbamate acts as a dehydrating agent, removing the water from active mass, thus preventing its reaction with urea and thereby shifting the equilibrium toward the urea side. In M/S Saipem process the optimum $\mathrm{N} / \mathrm{C}$ ratio is 3.2 to 3.5 .

Urea is produced by synthesis from liquid ammonia and gaseous carbon dioxide. Ammonia and carbon dioxide react to form ammonium carbamate, a portion of which dehydrates to form urea and water. The reaction of ammonium carbamate dehydration is influenced by the ratio of various reactants, operating pressure, temperature and residence time in reactor. The reaction of ammonia and carbon dioxide takes place in two stages to produce urea as following-

\section{$2 \mathrm{NH}_{3}+\mathrm{CO}_{2}=\mathrm{NH}_{2} \mathrm{COO} \mathrm{NH} 4+37.64 \mathrm{~K} \mathrm{Cal} /$ Mole \\ Ammonium Carbamate. \\ $\mathrm{NH}_{2} \mathrm{COO} \mathrm{NH} H_{4}=\quad \mathrm{NH} 2 \mathrm{CO} \mathrm{NH}{ }_{2}+\mathrm{H} 2 \mathrm{O}-6.32 \mathrm{~K} . \mathrm{Cal} / \mathrm{Mole} \ldots$. \\ Urea}

Reaction No. (1) Given above is instantaneous and completes very fast. It is exothermic in nature and $37.64 \mathrm{~K}$.Cal $/$ mole of heat is produced in the formation Ammonium Carbamate. Rate of formation of carbamate depends on the temperature and pressure. The rate increases with both temperature and pressure. At constant pressure, the rate increases with temperature, reaches the maximum and then rapidly decreasing up to zero value at the temperature corresponding to which the dissociation pressure equals the working pressure.

Reaction No.2, however, is very slow and controls the Urea formation. It is endothermic and $6.32 \mathrm{~K} . \mathrm{Cal} / \mathrm{Mole}$ is consumed in the dehydration of Ammonium Carbamate. A hypothetical process (not restricted by equilibrium conversion and phase equilibrium) at 1 atm and $25^{\circ} \mathrm{C}$. will, therefore, yield a net heat of $31.32 \mathrm{Kcal} /$ mole as shown above. 
Actual available heat in an ideal Urea Synthesis reaction will, however, is only approx. $5.74 \mathrm{Kcal} / \mathrm{mole}$ because of the heat lost in evaporation of liquid $\mathrm{NH}_{3}$, evaporation of water formed and melting of Urea. Moreover, to increase the conversion of the reactants, the synthesis is done at high pressure (approx. $160 \mathrm{Kg} / \mathrm{m} 2)$ and temperature $\left(180^{\circ} . \mathrm{C}\right)$, which needs feeding of $\mathrm{CO}_{2}$ and $\mathrm{NH}_{3}$ at high pressure. This is again an energy consuming process. Therefore, the overall urea production process becomes short in energy available from the reaction \& additional energy is put in to complete the process.

\section{Dissociation of Ammonium carbamate}

The dissociation pressure of carbamate increases rapidly with temperature and is of the order of $180 \mathrm{~kg} / \mathrm{cm} 2 \mathrm{a}$ at $200^{\circ} \mathrm{C}$. The dissociation pressure of carbamate is considerably increased when an excess of $\mathrm{CO} 2$ is used. The dissociation pressure is much less with excess ammonia. Thus, to maintain a high rate of formation of ammonium carbamate, a high temperature and hence, a high-pressure (above the dissociation pressure at this temperature) have to be maintained. The heat of formation must be dissipated in order to avoid the increase of temperature which corresponds to a dissociation pressure equal to the working pressure.

Dehydration of carbamate to urea

This is an equilibrium reaction and proceeds only in the liquid or solid phase and taking time. Rate of transformation of ammonium carbamate to urea without excess water or ammonia and $\mathrm{NH}_{3}: \mathrm{CO}_{2}$ ratio of $2: 1$ indicates that for carbamate conversion to urea increases with temperature.

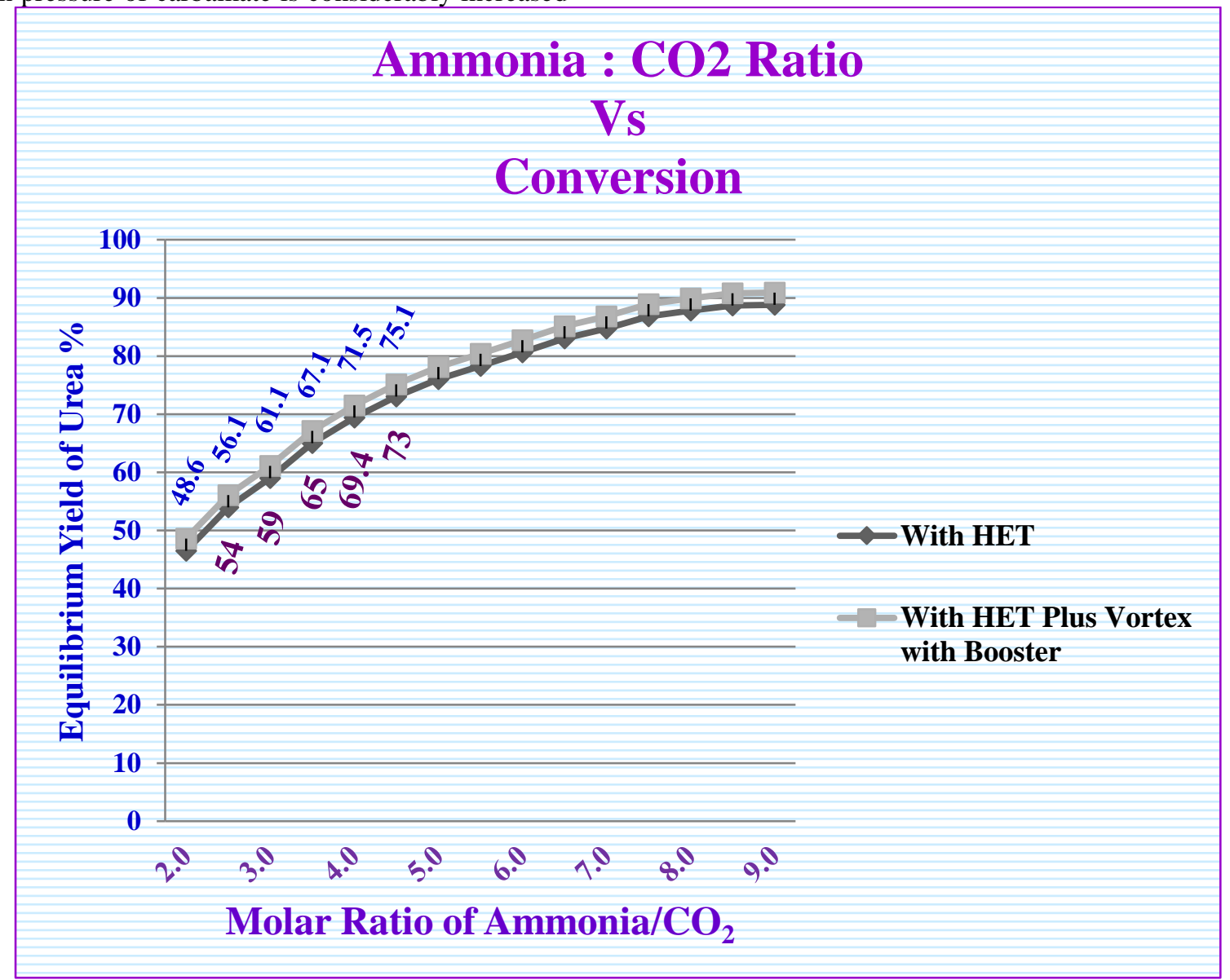

Fig. 2(N/C Ratio Vs. Conversion)

\section{H/C ratio}

Water is one of the products of reaction during transformation reaction of carbamate to urea. Its presence has a depressing effect on the conversion. In urea reaction one mole of water produce with one mole of urea hence any addition of water with the feed reduces the conversion according to "Le Chatelier's principle" Extra water from any other source has an adverse effect upon the concentration of urea. First, extra water occupies volume in the autoclave, thereby decreases its productive capacity. Second, extra water dilutes the urea solution, increases the load on the evaporation and increases energy consumption. But most important of all, excess water decrease the yield of urea as shown in the figure No.3. The presence of one mole of excess water per mole of carbamate cuts down the yield of urea by nearly half. The presence of excess ammonia over the $\mathrm{NH}_{3}: \mathrm{CO}_{2}$ ratio of 2:1 counter acts to a great extent the adverse influence of water. The formation of urea in homogeneous solutions is in no case dependant on the partial pressure of carbon dioxide, but that the conversion of carbamate into urea is directly proportional to the partial pressure of ammonia and inversely proportional to the partial pressure of water. 


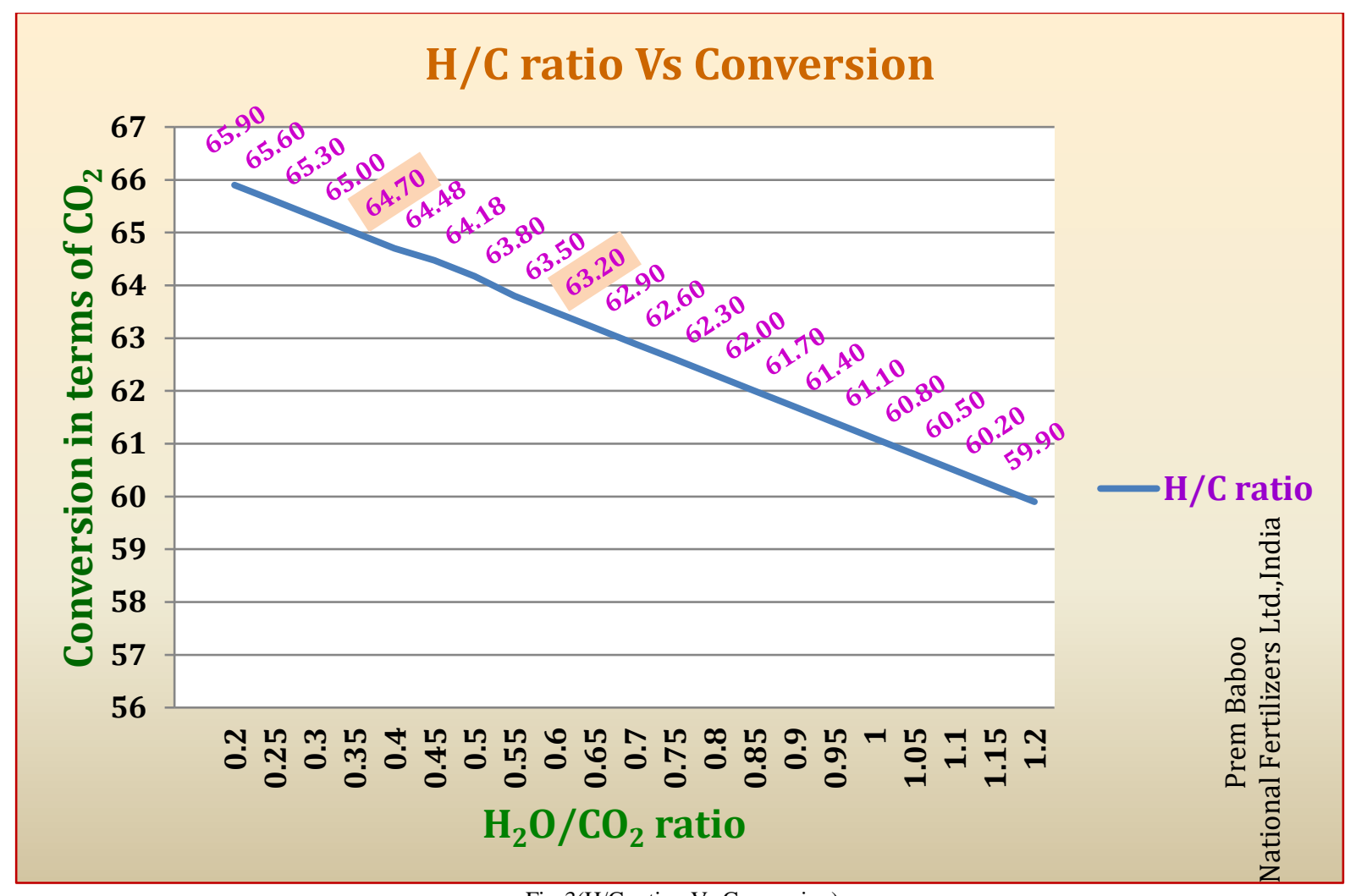

Fig-3(H/C ration Vs Conversion)

In the urea process the energy input to the process is mainly in the form of steam for stripping and the recycling of the unconverted reactants, water recycling and concentrating the solution. It is consumption of the steam, which can be saved by the optimization of process parameters and can be reduced water recycling into the reactor. The main focus area is to optimize the water recycle in the process and reduce the variability in process parameters mainly temperature at the outlet of each stage of decomposition and concentration common section distillation tower overhead product i.e. V8(reflux accumulator) concentration can be increased by reflux to C-2(distillation Tower) has been optimized. Major continuous contributors for water in the process streams other than the water generation through the formation itself, in a typical urea process following points as shown in the table-1, water sources may be optimized. The waste water section Reflux accumulator analysis given in table-2 may be optimized by reflux to rectification column. The better Concentration in Reflux accumulator better the advantages i.e. conversion of Urea reactor.

As water recycle to the urea reactor is a significant feature of urea manufacturing process thus reduction in water recycle has improved the operating efficiency of the plant. The optimization of water recycle should aim at to reduce the load of common section thereby steam. One mole of water is formed when one mole of urea is produced. Presence of excess water shifts the reaction equilibrium in reverse direction and yield of urea is reduced. However, water has to be added for recycling unconverted ammonia and $\mathrm{CO}_{2}$ back to the reactor. Lower the amount of water concentration in low pressure recovery section results in high concentration of carbamate and this causes pumping and choking problem in piping system. Excess water in reactor reduces effective volume for urea formation and additional energy is required in evaporation section. Study shows that presence of one mole of excess water per mole of carbamate reduces the equilibrium yield of urea by nearly one half. Extra water from any other source has an adverse effect upon the concentration of urea. First, extra water occupies volume in the autoclave, thereby decreases its productive capacity. Second, extra water dilutes the urea solution, increases the load on the evaporation and increases energy consumption. But most important of all, excess water decrease the yield of urea. The presence of one mole of excess water per mole of carbamate cuts down the yield of urea by nearly half. The presence of excess ammonia over the $\mathrm{NH}_{3}: \mathrm{CO}_{2}$ ratio of $2: 1$ counter acts to a great extent the adverse influence of water. The formation of urea in homogeneous solutions is in no case dependant on the partial pressure of carbon dioxide, 


\begin{tabular}{|c|c|c|c|c|c|c|c|}
\hline \multicolumn{8}{|c|}{ UREA LINE-II } \\
\hline \multicolumn{8}{|c|}{ WATER BALANCE IN UREA PROCESS } \\
\hline Sr.No. & DATE & & 18-Jun-18 & \multicolumn{2}{|c|}{ PLANT LOAD } & \multicolumn{2}{|c|}{$108.43 \%$} \\
\hline 1 & \multicolumn{5}{|l|}{ UREA PRODUCED PER HOUR } & 146.00 & $\mathrm{~T} / \mathrm{H}$ \\
\hline 2 & \multicolumn{5}{|c|}{ WATER PRODUCED IN UREA PROCESS } & 43.80 & $\mathrm{M}^{3} / \mathrm{HR}$ \\
\hline 3 & \multicolumn{5}{|c|}{ FROM P-2 (CARBAMATE PUMP) 31 unit, SEAL WATER FLOW } & & \\
\hline & $\mathrm{i}$ & \multicolumn{4}{|c|}{ WATER FLOW TO BOOSTER PUMP } & 0.30 & $\mathrm{M}^{3} / \mathrm{HR}$ \\
\hline & $\mathrm{ii}$ & \multicolumn{4}{|c|}{ WATER FLOW TO HP SEAL } & 0.30 & $\mathrm{M}^{3} / \mathrm{HR}$ \\
\hline & iii & \multicolumn{4}{|c|}{ WATER FLOW TO LP SEAL } & 0.30 & $\mathrm{M}^{3} / \mathrm{HR}$ \\
\hline 4 & \multicolumn{5}{|c|}{ FROM P-2 (CARBAMATE PUMP) 41 unit, SEAL WATER FLOW } & & \\
\hline & i & \multicolumn{4}{|c|}{ WATER FLOW TO BOOSTER PUMP } & 0.30 & $\mathrm{M}^{3} / \mathrm{HR}$ \\
\hline & ii & \multicolumn{4}{|c|}{ WATER FLOW TO HP SEAL } & 0.30 & $\mathrm{M}^{3} / \mathrm{HR}$ \\
\hline & iii & \multicolumn{4}{|c|}{ WATER FLOW TO LP SEAL } & 0.30 & $\mathrm{M}^{3} / \mathrm{HR}$ \\
\hline \multirow[t]{3}{*}{5} & \multicolumn{7}{|c|}{ P-1(AMMONIA FEED PUMP),PLUNGER WATER FLOW } \\
\hline & i & \multicolumn{3}{|c|}{$\mathrm{P}-1 \mathrm{~A} / \mathrm{B} / \mathrm{C}(\mathrm{ammonia}$ feed pump $)$} & 31 & 2.50 & $\mathrm{M}^{3} / \mathrm{HR}$ \\
\hline & ii & \multicolumn{3}{|c|}{$\mathrm{P}-1 \mathrm{~A} / \mathrm{B} / \mathrm{C}(\mathrm{ammonia}$ feed pump) } & 41 & 2.50 & $\mathrm{M}^{3} / \mathrm{HR}$ \\
\hline \multirow[t]{3}{*}{6} & \multicolumn{7}{|l|}{ FROM COMMON SECTION } \\
\hline & 31 FIC 168 FLOW M$^{3} / \mathrm{HR}$ & 31 & $\mathrm{NH}_{3} \%$ & 33.45 & WATER & 5.66 & $\mathrm{M}^{3} / \mathrm{HR}$ \\
\hline & $41 \mathrm{FIC} 169 \mathrm{FLOWM}^{3} / \mathrm{HR}$ & 41 & $\mathrm{NH}_{3} \%$ & 33.45 & WATER & 5.66 & $\mathrm{M}^{3} / \mathrm{HR}$ \\
\hline \multirow{2}{*}{7} & \multirow{2}{*}{ VACUUM } & \multirow{2}{*}{\multicolumn{3}{|c|}{ EJECTORS STEAM }} & 31 & 5.00 & $\mathrm{M}^{3} / \mathrm{HR}$ \\
\hline & & & & & 41 & 5.00 & $\mathrm{M}^{3} / \mathrm{HR}$ \\
\hline \multirow{2}{*}{8} & \multirow{2}{*}{ Pre-Concentrator } & \multirow{2}{*}{\multicolumn{3}{|c|}{ EJECTORS STEAM }} & 31 & 1.00 & \\
\hline & & & & & 41 & 1.00 & \\
\hline \multirow{2}{*}{9} & ALL LT,P-17(Stripper DP cell & & С DT DUPCE У & FI OW & 31 & 1.00 & $\mathrm{M}^{3} / \mathrm{HR}$ \\
\hline & flushing) & & 1, PI PUKGE & FLUW & 41 & 1.00 & $\mathrm{M}^{3} / \mathrm{HR}$ \\
\hline & & $\begin{array}{l}\text { WAT } \\
\text { WAS }\end{array}$ & $\begin{array}{l}\text { R FLOW TO } \\
\text { IING COLUM }\end{array}$ & ERTS & 31 & 0.80 & $\mathrm{M}^{3} / \mathrm{HR}$ \\
\hline 10 & FIC 103 & $\begin{array}{l}\text { WAT } \\
\text { WAS }\end{array}$ & $\begin{array}{l}\text { R FLOW TO } \\
\text { IING COLUM }\end{array}$ & ERTS & 41 & 0.80 & $\mathrm{M}^{3} / \mathrm{HR}$ \\
\hline 11 & & 104 & er to $I$ P sectic $s$ s & bino column) & 31 & 0.00 & $\mathrm{M}^{3} / \mathrm{HR}$ \\
\hline 11 & & 104(w- & er to L.P. sectic & hing column) & 41 & 0.00 & $\mathrm{M}^{3} / \mathrm{HR}$ \\
\hline 12 & FROM E & ING I & Ist Recovery S & & & 2.50 & $\mathrm{M}^{3} / \mathrm{HR}$ \\
\hline & & AL W & TER FLOW & & & 80.03 & $\mathrm{M}^{3} / \mathrm{HR}$ \\
\hline 13 & AMMONIA & & & & & 5.04 & $\mathrm{M}^{3} / \mathrm{HR}$ \\
\hline 14 & $\mathrm{CO}_{2}$ & & & & & 2.27 & $\mathrm{M}^{3} / \mathrm{HR}$ \\
\hline 15 & UREA & & & & & 0.96 & $\mathrm{M}^{3} / \mathrm{HR}$ \\
\hline & TOTAL C-2 FEED & & & & & 88.30 & $\mathrm{M}^{3} / \mathrm{HR}$ \\
\hline & TOTAL C-2 FEED IN DAY & & & & & 2119 & $\mathrm{M}^{3}$ \\
\hline
\end{tabular}

Table -1 (Water balance in Urea Plant)

But that the conversion of carbamate into urea is directly proportional to the partial pressure of ammonia and inversely proportional to the partial pressure of water.

\begin{tabular}{|l|c|c|c|}
\hline V-6 (Waste water tank) Analysis & $\%$ & V-8 (Reflux Accumulator) Analysis & $\%$ \\
\hline AMMONIA, $\%$ & 6.3 & AMMONIA & 33.45 \\
\hline $\mathrm{CO}_{2}, \%$ & 2.8 & $\mathrm{CO}_{2}$ & 15.053 \\
\hline UREA $\%$ & 1.2 & WATER & 51.49 \\
\hline WATER & 89.7 & & \\
\hline
\end{tabular}

Table -2(Waste water analysis)

In urea process steam is given too many ejectors and which goes to direct process in waste water section. In distillation (waste water section) not only load on steam requirement but also increase the water recycle to reactor. In table No-3 shows the ejectors steam water balance. 


\begin{tabular}{|c|c|c|c|}
\hline \multicolumn{4}{|c|}{ Steam Balance of Urea-II Plant } \\
\hline \multirow{2}{*}{\multicolumn{4}{|c|}{$\begin{array}{l}\text { Dated: } 23.05 .2018 \\
\text { KS(108 ata) STEAM }\end{array}$}} \\
\hline & & & \\
\hline \multirow{4}{*}{ KS import from A-II } & \multirow{4}{*}{147.2} & KS to $31 \mathrm{TK}-1$ & 75.0 \\
\hline & & KS to 41TK-1 & 72.2 \\
\hline & & KS to MS L/d (31PV-266) & 0.0 \\
\hline & & KS to MS L/d (41PV-266) & 0.0 \\
\hline Total Generation & 147.2 & Total Consumption & 147.2 \\
\hline \multicolumn{4}{|l|}{ HS(40 ata) STEAM } \\
\hline HS import from A-II & 12 & HS to Hydrolyser(R-2) & 7.5 \\
\hline \multirow{2}{*}{ (1) } & & HS to MS L/d(31-Stream) & 2.5 \\
\hline & & HS to MS L/d(41-Stream) & 1.5 \\
\hline Total Generation & 12 & Total Consumption & 12 \\
\hline \multicolumn{4}{|l|}{ MP(24 ata) STEAM } \\
\hline Ext. Steam from $31 \mathrm{TK}-1$ & 57.0 & MS to 31 E-1(stripper) & 48.0 \\
\hline Ext. Steam from 41TK-1 & 48.0 & MS to 41 E-1(Stripper) & 48.0 \\
\hline HS to MS L/d(31-Stream) & 2.5 & MS to 31 E-2(MP Decomposer) & 8.0 \\
\hline HS to MS L/d(41-Stream) & 1.5 & MS to 41 E-2 (MP Decomposer) & 8.0 \\
\hline Steam generation in $31 \mathrm{~V}-29$ (stripper Cond sep) & 3.0 & $31 \mathrm{MS}$ to $\mathrm{LS} \mathrm{L} / \mathrm{d}(42.5 \%)$ & 1.5 \\
\hline Steam generation in $41 \mathrm{~V}-29$ (stripper Cond sep) & 3.0 & $41 \mathrm{MS}$ to LS L/d(42.5\%) & 1.5 \\
\hline Total Generation & 115 & Total Consumption & 115 \\
\hline \multicolumn{4}{|l|}{ LS(4.0 ata) STEAM } \\
\hline 31-E5 Generation with de super heating & 47.0 & LS to 31 E-3 (LP Decomposer) & 9.0 \\
\hline 41-E5 Generation with de super heating & 47.0 & LS to 41 E-3 (LP Decomposer) & 9.0 \\
\hline $31 \mathrm{MS}$ to $\mathrm{LS} \mathrm{L} / \mathrm{d}(42.5 \%)$ & 2.0 & LS to 31E-14(1st stage vacuum Heat exchanger) & 12.5 \\
\hline 41MS to LS L/d(42.5\%) & 1.5 & LS to 41E-14 (1st stage vacuum Heat exchanger) & 12.5 \\
\hline LS import from CPP & 0.0 & LS to 31E-15(2nd stage vacuum Heat exchanger) & 6.5 \\
\hline \multirow{9}{*}{\multicolumn{2}{|c|}{ L.S.(Low pressure Steam) Network }} & LS to 41E-15 (2nd stage vacuum Heat exchanger) & 6.5 \\
\hline & & LS to 31Vac. Ejectors & 5.0 \\
\hline & & LS to 41Vac. Ejectors & 5.0 \\
\hline & & LS to C-2(Distillation Tower) & 11.5 \\
\hline & & LS to 31Steam Jacketing & 3.0 \\
\hline & & LS to 41Steam Jacketing & 2.5 \\
\hline & & LS to $31 \mathrm{EJ}-53$ & 6.0 \\
\hline & & LS to 41EJ-53 & 6.0 \\
\hline & & 31/41 EJ-(101/102) & 3.0 \\
\hline Total Generation & 98 & Total Consumption & 98.0 \\
\hline
\end{tabular}

In the conventional total recycle process carbamate is decomposed in low pressure stages. The gases so released are condensed in process water and the resulting concentrated carbamate is pumped back to the reactor. In stripping process, the heat of condensation, which is equivalent to about 1 ton of steam per ton of urea, evolved at low temperature, is carried off by cooling water. Moreover, the process water required for condensation reduces the conversion efficiency to an appreciable extent.

In the stripping process, the decomposition of most unconverted ammonium carbamate is carried out at the reactor pressure by stripping off the reactor solution with fresh carbon dioxide gas. The off-gas from the stripper consisting mainly of $\mathrm{CO}_{2}$ and ammonia is condensed forming liquid carbamate at reactor pressure and a temperature in excess of the melting point of ammonium carbamate. Therefore, the addition of water is not necessary. The heat of condensation is not removed by cooling water but LP steam is generated. In the conventional total recycle process, a large excess of ammonia is used for the control of temperature in the reactor. Besides, the excess ammonia increases the conversion efficiency. The same result is obtained in stripping process by maintaining the controlled $\mathrm{NH}_{3}: \mathrm{CO}_{2}$ ratio of 2.9 to 3.5 in stripping process as against the 4.0 in conventional recycle process.
In the conventional total recycle process, the operating conditions of pressure and temperature are severe. The usual pressure range is $200-400 \mathrm{~kg} / \mathrm{cm} 2 \mathrm{~g}$ and the operating temperature range is $190-200^{\circ} \mathrm{C}$. At such elevated pressure and temperature, the susceptibility of metals to attack by reactants is pronounced and operation of lead lined and silver lined reactors were not satisfactory. Passivation of stainless steel by oxygen has, however, met with great success up to reactor temperature of about $195^{\circ} \mathrm{C}$. Beyond this; zirconium lining had to be adopted. In the stripping process, the advantage is derived from the fact that the stainless steel which is much cheaper than other liners, has been used because the operating conditions are not so severe. The pressure is in the range of $140-158 \mathrm{~kg} / \mathrm{cm} 2 \mathrm{~g}$ and the temperature is about $170-190^{\circ} \mathrm{C}$, which are very safe limits for using stainless steel. Research and development in urea process technology is contributing towards energy conservation and pollution control. Limited energy sources and statutory demands for environment protection have reflected in the development of new urea processes.

Water is one of the products of reaction during transformation reaction of carbamate to urea. Its presence has a depressing effect on the conversion. Any addition of water with the feed reduces the conversion. One mole of water is formed when one mole of urea is produced. Presence of excess water shifts the reaction equilibrium in reverse direction and yield of urea 
is reduced. However, water has to be added for recycling unconverted ammonia and $\mathrm{CO}_{2}$ back to the reactor. Lower the amount of water concentration in low pressure recovery section results in high concentration of carbamate and this causes pumping and choking problem in piping system. Excess water in reactor reduces effective volume for urea formation and additional energy is required in evaporation section. Study shows that presence of one mole of excess water per mole of carbamate reduces the equilibrium yield of urea by nearly one half.

Extra water from any other source has an adverse effect upon the concentration of urea. First, extra water occupies volume in the autoclave, thereby decreases its productive capacity. Second, extra water dilutes the urea solution, increases the load on the evaporation and increases energy consumption. But most important of all, excess water decrease the yield of urea. The presence of one mole of excess water per mole of carbamate cuts down the yield of urea by nearly half. The presence of excess ammonia over the $\mathrm{NH}_{3}: \mathrm{CO}_{2}$ ratio of $2: 1$ counter acts to a great extent the adverse influence of water. The formation of urea in homogeneous solutions is in no case dependant on the partial.

\begin{tabular}{|c|c|c|}
\hline \multicolumn{3}{|c|}{ Steam Condensate Balance of Urea-II Plant } \\
\hline Sr. No. & Source of Condensate & Quantity, $\mathrm{m}^{3} / \mathrm{h}$ \\
\hline 1 & Steam Condensate from 31 E-2(MP Decomposer) & 8 \\
\hline 2 & Steam Condensate from 41 E-2 (MP Decomposer) & 8 \\
\hline 3 & Steam Condensate from 31E-3 (LP Decomposer) & 9 \\
\hline 4 & Steam Condensate from 41E-3 (LP Decomposer) & 9 \\
\hline 5 & Steam Condensate from 31E-14(1st stage vacuum Heat exchanger) & 12.5 \\
\hline 6 & Steam Condensate from 41E-14 (1st stage vacuum Heat exchanger) & 12.5 \\
\hline 7 & Steam Condensate from 31E-15(2nd stage vacuum Heat exchanger) & 6.5 \\
\hline 8 & Steam condensate from 31E-15(2nd stage vacuum Heat exchanger) & 6.5 \\
\hline 9 & Steam Condensate from 31EJ-53(Pre decomposer) & 6 \\
\hline 10 & Steam Condensate from 41EJ-53(Pre decomposer) & 6 \\
\hline 11 & Steam Condensate from 31 Steam Jacketing & 3 \\
\hline 12 & Steam Condensate from 41 Steam Jacketing & 3 \\
\hline & Total steam Condensate & 90 \\
\hline \multicolumn{3}{|c|}{ STEAM CONDENSATE GOES TO PROCESS } \\
\hline 1 & STEAM CONDENSATE TO 31 P-2 A/B BOOSTER/HP/LP SEAL & 1.1 \\
\hline 2 & STEAM CONDENSATE TO 41 P-2 A/B BOOSTER/HP/LP SEAL & 1.1 \\
\hline 4 & 31 P-1 A/B/C(AMMONIA FEED PUMP) & 2.5 \\
\hline 5 & 41-P-1 A/B/C(AMMONIA FEED PUMP) & 2.5 \\
\hline 6 & $31 \mathrm{LT} / \mathrm{PT}$ purge water flow & 1 \\
\hline 7 & $31 \mathrm{LT} / \mathrm{PT}$ purge water flow & 1 \\
\hline 8 & 31 FIC 103 (inerts washing Column) & 1 \\
\hline 9 & 31 FIC 103 (inerts washing Column) & 1 \\
\hline 10 & Condensate to $31 / 41 \mathrm{~L} . \mathrm{S}$ de super heater & 5 \\
\hline & Total Condensate goes to Process & 16.2 \\
\hline & Net Steam Condensate export & 73.8 \\
\hline \multicolumn{3}{|c|}{ TURBINE CONDENSATE TO D.M. PLANT } \\
\hline 1 & STEAM CONDENSATE FROM 31 TURBINE,MT & 19 \\
\hline 2 & STEAM CONDENSATE FROM 31 TURBINE,MT & 21 \\
\hline \multicolumn{2}{|r|}{ TOTALTO D.M PLANT,MT } & 40 \\
\hline
\end{tabular}




\begin{tabular}{|c|c|c|c|c|c|c|}
\hline Plant load & $108.00 \%$ & Date & $14-02-2018$ & \multirow{2}{*}{$\begin{array}{l}\text { Ammonia to } \mathrm{CO}_{2} \\
\text { ratio }\end{array}$} & \multirow[b]{2}{*}{$\begin{array}{l}\text { Percentage } \\
\text { Conversion }\end{array}$} & \multirow{2}{*}{$\begin{array}{l}\text { KS Consumption, } \\
\text { Ton }\end{array}$} \\
\hline \multicolumn{2}{|l|}{ Parameters } & $\begin{array}{c}\text { Reactor outlet analysis, } \\
\text { weight } \% \\
\end{array}$ & $\begin{array}{l}\text { Water to } \mathrm{CO}_{2} \\
\text { ratio }\end{array}$ & & & \\
\hline \multicolumn{2}{|l|}{ Ammonia } & $34.00 \%$ & \multirow{4}{*}{0.4} & \multirow{4}{*}{3.5} & \multirow{4}{*}{64.7} & \multirow{4}{*}{3560} \\
\hline \multicolumn{2}{|c|}{ Carbon Dioxide } & $13.99 \%$ & & & & \\
\hline \multicolumn{2}{|c|}{ Urea } & $32.82 \%$ & & & & \\
\hline \multicolumn{2}{|l|}{ Water } & $19.99 \%$ & & & & \\
\hline Plant load & $108.00 \%$ & Date & $27-03-2018$ & \multirow{2}{*}{$\begin{array}{l}\text { Ammonia to } \mathrm{CO}_{2} \\
\text { ratio }\end{array}$} & \multirow{2}{*}{$\begin{array}{l}\text { Percentage } \\
\text { Conversion }\end{array}$} & \multirow{2}{*}{$\begin{array}{l}\text { KS consumption, } \\
\text { Ton }\end{array}$} \\
\hline \multicolumn{2}{|l|}{ Parameters } & $\begin{array}{c}\text { Reactor outlet analysis, } \\
\text { weight } \%\end{array}$ & $\begin{array}{l}\text { Water to } \mathrm{CO}_{2} \\
\text { ratio }\end{array}$ & & & \\
\hline \multicolumn{2}{|l|}{ Ammonia } & $33.20 \%$ & \multirow{4}{*}{0.65} & \multirow{4}{*}{3.5} & \multirow{4}{*}{63.2} & \multirow{4}{*}{3670} \\
\hline \multicolumn{2}{|c|}{ Carbon Dioxide } & $14.00 \%$ & & & & \\
\hline \multicolumn{2}{|l|}{ Urea } & $35.00 \%$ & & & & \\
\hline \multicolumn{2}{|l|}{ Water } & $17.00 \%$ & & & & \\
\hline
\end{tabular}

\section{Calculation}

From table No-5, The $\mathrm{H} / \mathrm{C}$ ratio changing from $0.65 \%$ to $0.40 \%$, the conversion improved $1.5 \%$

KS (108 bar steam) consumption difference, 3670-3560

$=110$ Ton, Enthalpy of 108 bar steam is $0.810 \mathrm{G} . \mathrm{cal} / \mathrm{ton}$,

Total Enthalpy=110 X 0.810=89.1 G.cal.

Saving, G.cal cost $=\$ 47.10$ (in case of Natural gas used)

Hence Saving=89.1X \$47.1=\$4196.6, per day saving

And annually saving $=\$ 4196.6$ X $365=\$ \mathbf{1 5 3 1 7 6 3}$

\section{RESIDENCE TIME}

Urea conversion reaction is slow and takes 20 minutes to attain equilibrium. Considering the slowness of the reaction, urea reactor is so designed that residence time should be more than 20 minutes. Higher residence time favours equilibrium conversion and normally reactors are designed for residence time of 30 minutes to one hour, depending upon other operating parameters. Residence time in urea reactor plays an important role on equilibrium conversion. When operating parameters including mole ratio are not favourable for a good yield, higher residence time compensates to some extent to achieve a better yield. But this is done by providing a higher reactor volume, which increases capital investment.

The residence time $=$ Reactor Volume/Feed Volume

Hence reactor volume is constant; the residence time depends upon plant load.

Residence Time for urea line-II

Reactor Volume $=134 \mathrm{~m}^{3}$

Feed Volume $=235.9 \mathrm{~m}^{3} / \mathrm{Hr}$. (Assume all reactants are in

liquid state)

Residence time $=$ Reactor Volume $/$ Feed Volume

At 3231 TPD (design Data)

Residence time $=134 / 235.69$

$=0.5685 \times 60 \mathrm{~min}$

$34.11 \mathrm{~min}$.

On dated 23/02/2018,

At 3500 TPD plant Load, Feed Volume $=255.31 \mathrm{~m}^{3} / \mathrm{hr}$.

The residence time reduce to $=134 / 255.31=0.525$

Hence Residence time $=0.525$ X $60 \mathrm{Min}=31.5 \mathrm{~min}$.

Residence time Increase with installing vortex mixture with Conversion Booster

Due to more efficient carbamate formation reaction and reduction of gas liquid volume when the gas turns into liquid media in reactor bottom, residence time in urea reactor is increased. The bi-phase passed into conversion booster like tubular reactor, after that the $2^{\text {nd }}$ reaction immediately start and actual residence time increases. The gas phase converted into liquid phase immediately hence the driving force acts on fluid dynamics.

4. Reactors internals replaced with advance Technology.

Now a days the philosophy has been changed. Introduction of better internals like HET, mixing equipment's booster conversion like sets of tubular reactor. This reaction requires smaller area so the extra area is used for the second reaction, which is formation of urea. Ultimately, it results in efficiency enhancement of the reactor, increase of $\mathrm{CO}_{2}$ conversion, utility saving of steam, recycling reduced. In HET reactors the effective volume of second reaction is less than NIIK internals reactor as shown in the figure-4. During its research into reactor design, NIIK carried out model trials of all types of conventional mixers applied in urea reactors in a specially designed scale-down laboratory urea reactor. Based on the tests it was concluded that no conventional mixers ensure the necessary mixing of the components. Gas in the form of large bubbles rises up reducing the specific surface of the media contact of gas and liquid. In this case the fill factor of the bottom part is low. This process results in an extension of the Ammonium carbamate formation zone and further reduces the efficiency of the entire synthesis process. To ensure efficient mixing of feedstock in the reactor inlet NIIK offers a high efficiency vortex mixer. The working principle of the mixer is based on the effect of intensive dispersion of gas resulting from the breaking of a swirling gas-liquid jet with liquid at the nozzle outlet. Due to the unique design of the vortex mixer, the dispersion of the gas into the liquid is carried out more efficiently - the bubbles are much smaller than the ones produced in conventional mixers. In this case the specific surface of the media contact generated by the vortex mixer is two times higher. In India Numbers of Vortex mixture with conversion booster installed in many plants. Different licensers provided different type of internals. e.g. Siphon jet pump, Casale high efficient trays, Super cup HET etc.

Saving from Vortex mixture and Conversion Booster The Medium Pressure Steam (24bar) saved about $75 \mathrm{Kg}$ to $80 \mathrm{~kg}$ per ton of urea 
Suppose Production $=3500$ TPD

Total steam saving $=75$ X $3500=262500 \mathrm{~kg}=262.5$ Ton

Enthalpy of M.S.=0.670 G.Cal /Ton of 24 bar steam

Enthalpy $=262.5$ X 0.670 G.Cal $=175.875$ G.cal.

OR Saving of Energy=175.875/3500=0.05 G.Cal/ton of urea.
Cost of Energy $($ Natural Gas) $=\$ 11.87 /$ MMBTU (June 2018) (1 MMBTU=0.252 G.cal)

Now rate of G.cal $=11.87 / 0.252=\$ 47.10$

Total Saving $=175.875 X 47.10=\$ 8283.7$ per day saving. In 365 days, $365 X \$ 8283.7=\$ 3023550.5$

Hence the payback period will be very less

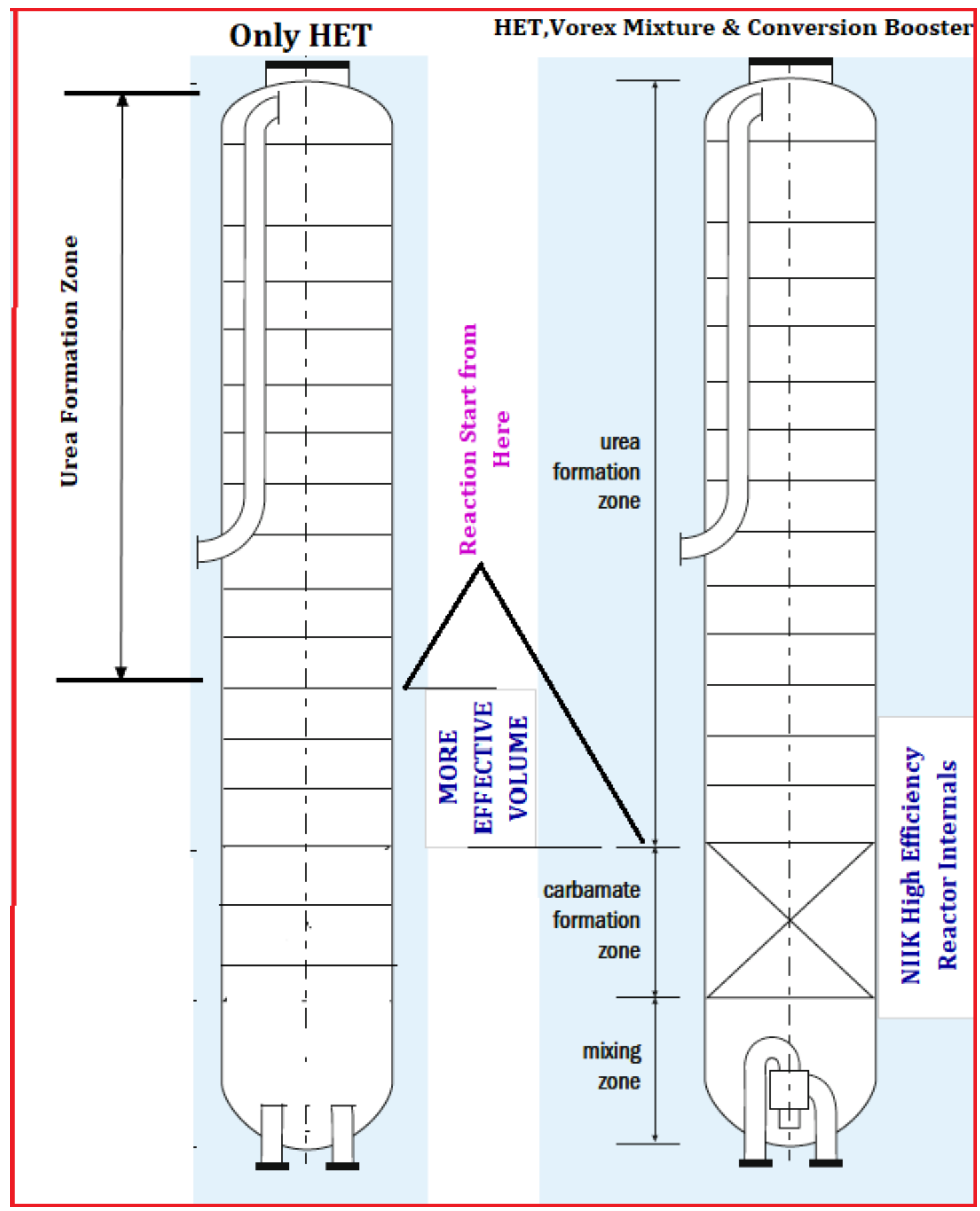

Fig. 4 (comparison of HET reactor and NIIK Internals reactor)

\section{CONCLUSION}

Based on the observations described above, it can be concluded that the energy can be saved by small practices in the plant. If you have balance of water in process by small practices, then you will get definitely advantages of energy savings. The revamp with new technology is very beneficial and payback period hardly one year or less. The net improvement of the $\mathrm{CO}_{2}$ conversion in an existing plant has, in fact, the advantages are: reduction of steam requirements in downstream of the plant less recycling and better product 
quality. Based on its proven features, the internals represent a completely innovative reaction device for urea synthesis that can be advantageously applied to design a new generation of urea reactors as well as to improve the performance of existing equipment in retrofit design. In case you are interested, the above companies are willing to evaluate the performance of your synthesis and determine the potential improvements of your plant. Those plants which have problem of bottleneck and high energy the Vortex mixture with Conversion Booster and NIIK internals may be installed in urea reactor, after that the energy will be come down about 0.04-0.07 G.cal /tone of urea as per process and plant load. For Vortex mixture may contact to NIIK, Russia, Oleg Kostin (Mr) General Director Tel: +7 (8313) 26-40-88. NIIK, R\&D Institute of Urea, 31 Griboedov street,Dzerzhinsk,Nizhny Novgorod region 606 008, Russia.

\section{Legends}

KS-108 bar steam, HS-40 bar steam, MS-medium pressure steam (24 bar steam), LS-Low pressure steam (4.0 bar steam), TPD -ton per day, G.Cal-Giga calorie. HP-high pressure, MP- medium pressure, LP- low pressure. N/C RatioAmmonia to $\mathrm{CO}_{2}$ ratio, $\mathrm{H} / \mathrm{C}$ Ratio-water to $\mathrm{CO}_{2}$ ratio. Hr.Hour, K. Cal-Kilo calorie.

\section{REFERENCES}

[1] Urea reactor revamping, Enhanced Urea Reactor, Nitrogen +Syngas 332 | November - December 2014.

[2] The Snamprogetti TM Super Cups Solution. Nitrogen + Syngas 2016 International Conference (Berlin, 29 February - 3 March 2016)

[3] Stamicarbon pure knowledge paper 431W Siphon Jet Pump.

[4] Urea Reactor Trays to Increase Plant Capacity and Efficiency, Ammonia Technical Manual 1997

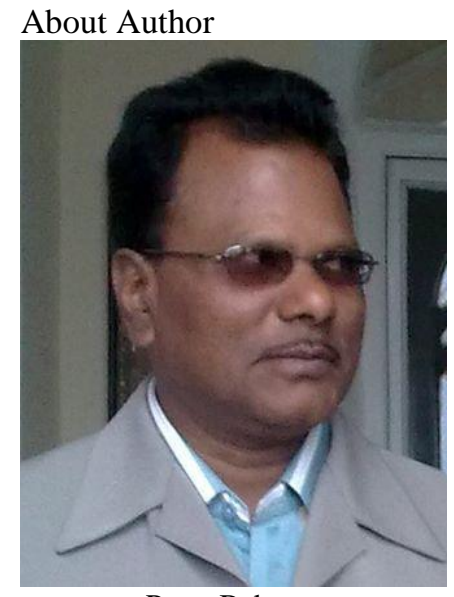

Prem Baboo

The author is working in National Fertilizers Ltd. India and active member of American Institute of Chemical Engineering (AIChE), New York, USA. Fellow of Institution of Engineers, India. Reviewer of International Journal of Engineering Research and Technology (IJERT). Sr. advisor of www.ureaknowhow.com where the Urea industry meets. 